\title{
Corynebacterium afermentans
}

National Cancer Institute

\section{Source}

National Cancer Institute. Corynebacterium afermentans. NCI Thesaurus. Code C86307.

A species of aerobic or facultatively anaerobic, Gram-positive, coryneform, pleomorphic bacilli assigned to the phylum Actinobacteria. This species is nonmotile, non-spore forming, catalase positive, oxidase, urease, indole and esculin negative, does not reduce nitrate, is non-fermenting, non-acid fast, and does not produce hydrogen sulfide; some subspecies are lipophilic and others non-lipophilic. C. afermentans is commensal, but can become pathogenic and has been associated with prosthetic valve endocarditis. 